\title{
Corrosion Degradation of Two Coating Systems Exposed for Three Years in a Tropical Oceanic Atmospheric Environment
}

\author{
Baihui Shang ${ }^{1,2, *}$, Lunwu Zhang ${ }^{1,3}$, Yuqin $\mathrm{Zhu}^{1}$, Shuai $\mathrm{Wu}^{1}$, Junpeng Teng ${ }^{1}$, Qiongyao He ${ }^{1,3}$, Yan Su ${ }^{1,3, *}$ \\ ${ }^{1}$ Southwest Technology and Engineering Research Institute, Chongqing, 400039, PR China \\ ${ }^{2}$ School of Material Science and Technology, Yingkou Institute of Technology, 115014, PR China \\ ${ }^{3}$ Wanning Hainan, Material Corrosion in Atmospheric Environment, National Observation and \\ Research Station, Wanning, 571500, PR China \\ *E-mail: bhshang12s@alum.imr.ac.cn, suyan71@126.com
}

doi: $10.20964 / 2021.01 .67$

Received: 16 September 2020 / Accepted: 3 November 2020 / Published: 30 November 2020

Two commercial coating systems applied to aluminum alloy screw connections exposed naturally in a tropical oceanic atmospheric environment were studied. The degradation process after different exposure times was analyzed by a series of test methods: visual appearance, color change, gloss loss, Surface FTIR and EIS. Our experimental results indicated that for the screw connection structure, the joint area was not only more susceptible to corrosion, but also increased the inconsistency of the flat area nearby. The protective ability of coating system 1 was superior to that of coating system 2 . The effective protective time of coating system 1 was about two years, while the coating system 2 was less than one year.

Keywords: Natural Exposure Test; Coating Systems; Degradation; Protective Ability

\section{$\underline{\text { FULL TEXT }}$}

(C) 2021 The Authors. Published by ESG (www.electrochemsci.org). This article is an open access article distributed under the terms and conditions of the Creative Commons Attribution license (http://creativecommons.org/licenses/by/4.0/). 